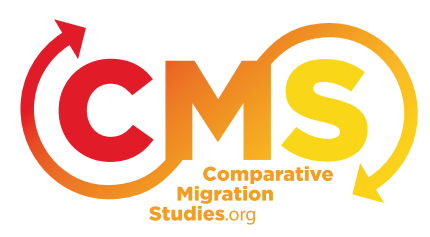

\title{
Comparisons in Migration Studies
}

\author{
Marco Martiniello
}

\author{
CMS 1 (1): 7-22 \\ DOI: 10.5117/CMS2013.1.MART
}

\begin{abstract}
The paper presents and critically discusses the different types of comparison developed in migration studies with a special attention to European literature. It then identifies missing topics and issues to be covered by comparative research in the field by focussing on European and on North American research.
\end{abstract}

Keywords: migration, post-migration dynamics, migration studies, comparative research

\section{Introduction}

In the current age of migration (Castles and Miller, 2009), research remains fragmented in different ways. The first line of fragmentation is between migration studies and post-migration studies. On the one hand, some scholars examine migration flows and patterns of human mobility. They try to understand and/or explain why people move, how many do so, where they go, what is their itinerary and what policies are designed in order to manage international and internal population movements.

On the other hand, other researchers focus on what I call the postmigration situation (Martiniello, 2012). The expression refers to what happens when migrants enter a new country and settle there. The focus here is on the examination of how they find a place, and on how they are allocated one, in their new society. Do they integrate, assimilate, form distinct societies beside the mainstream society? How are they perceived and treated by the local citizens? Do they face discrimination, racism? Are they accepted, tolerated, incorporated, excluded? Do they have access to citizenship and rights? What are the policies developed to respond to their 
presence: integration policies, assimilation policies, multicultural policies, etc.? To put it simply, a part of the research community is interested in migration flows and movements and the other part deals more with migration stocks in the host societies as if there was a sharp analytical distinction between migration movements and migrant integration. This traditional distinction between migration and post-migration studies is not always and everywhere as sharp as I have described, but it remains problematic. The fact that specialists of migration movements and specialists on the various issues linked to integration do not usually work together rests on the illusion that migration flows and integration are somewhat distinct phenomena that can be studied separately. However, it seems undisputable that migration and integration are strongly related.

The conditions under which migration movements occur have an impact on the range of opportunities of integration in the new country. For instance, leaving ones' country and entering the new country clandestinely do not provide the same opportunities of integration as being admitted as a high-skilled worker. It is therefore fruitful to look at the migration process globally by considering both the modalities of movements and the modalities of establishment in a new society as well as the links that the migrant may keep with the country of origin. Fortunately, Comparative Migration Studies understands migration in a comprehensive way. The contributions to this first issue deal both with migration dynamics and with different dimensions (social, economical, political and cultural dimensions including immigrant integration, assimilation, ethnicity formation and racism) of the post-migration situation. This is certainly an added value of the new journal.

Considered globally, migration and post-migration studies is a multidisciplinary research field dominated by North American scholarship even though research has developed on all the continents and notably in Europe. Until recently, research was strictly anchored in the nation-state experience of the receiving countries. The well established national research traditions in the field that defined a methodological nationalism that was challenged by scholars advocating a transnational perspective in the 199os but before that, by the Algerian-French sociologist Abdelmalek Sayad in his famous article Immigration and State Thought. He argued, "to about migration is always to think about the state, and more precisely, it is to think about the state that thinks about migration" (Martiniello and Rath, 2010). 
It is important to bear in mind these important characteristics when starting a discussion on comparative research on migration and post-migration situations, which is the topic of this article. The place of comparison varies from one discipline to another. The type of relevant comparison is not the same in nationally anchored research and in transnational research. However, comparative studies have always played a crucial role in the development of migration and post-migration studies alongside single case studies of specific migration groups or migration experiences, on the one had, and overarching theories of migration and incorporation, on the other hand. In a way, in the field (as in other social science fields) it is very difficult not to compare even when comparison is not systematized or even when it remains implicit. Generalisation cannot be reached without comparisons. According to John Stanfield II, "The best social scientific work is comparative. This is because, whether we are trying to explain something about the world or to predict future trends and tendencies, our arguments are strongest when we are able to bring to the table evidence drawn from more than one case" (Stanfield II, 1993:25). Surprisingly, there are not that many publications addressing specifically the pros and cons of comparison in migration and post-migration studies. Recently, (Bloemraad, 2013) and (Fitzgerald, 2012) have specifically discussed theses issues. This article may be read as a complement to their very interesting insights into the status of comparison and the ways to carry out comparative research in the field of migration. This article does not address the issue of comparative research designs. It does not respond to the question of how we compare, which is well covered by (Bloemraad, 2013). Nor does it discuss the issues of comparative field research as advocated by (Fitzgerald, 2012).

In this general context, the article pursues two main aims. The first aim is to critically discuss the different types of comparison developed in migration and post-migration studies with a special attention to European literature. The second aim is to identify missing topics and issues to be covered by comparative research in the field. The focus of the second part will be on European and on North American research even though the comparative scope of the journal is much broader. 


\section{The types of comparative research in migration and post-migration studies}

Four main types of comparative research can be found in the literature on migration and post-migrations situations by asking a very simple question: what do researchers compare? They compare people, places, periods of time and less importantly insights from different academic disciplines in relation to one or several of the research topics and issues that have been explored over time, from migration patterns to political participation of migrants, just to mention two examples.

\section{Comparing people}

As migration and post-migration research has historically developed within the nation-state framework, comparative research has first logically dealt with people present on the national territory of the receiving countries. Lots of comparisons have been made between immigrant national and ethnic groups. In the USA, a significant part of the literature has tried to explain the differences and similarities between the integration and assimilation patterns of the various national, ethnic and racial groups in American cities (Steinberg, 2001). Do the Irish integrate better than the Italians? Are there differences in the labour market incorporation of Mexicans and African-Americans? How to account for the differences in the naturalization process of different nationalities? Many European scholars followed the same type of national, ethnic and racial comparisons. In Belgium and the Netherlands, for example, it is very usual to compare at least Moroccan and Turkish immigrants and their offspring on many different topics like political participation (Tillie, 1998), school performance or unemployment. More recently, as a consequence of the European integration process, many studies have compared EU mobile citizens, who are not labelled migrants anymore, and third-countries nationals.

These national, ethnic and racial group-to-group comparisons are interesting because they show that the migration process does not affect all national groups of migrants in the same way. However, this can be misleading in at least two ways. First, they often fall into the trap of culturalization and essentialization of migrant groups and consequently uncritically privilege culture as the major explanatory dimension of the phenomena under examination. Actually, choosing to compare national and ethnic groups 
often assumes from the start a culturalist approach to the migration process. Since national and ethnic groups are seen as characterized by a distinctive culture and identity, choosing to compare them with reference to their migration process or a particular dimension of their integration expresses the endorsement of the hypothesis that culture not only matters but that it is the most relevant variable to explain similarities and differences in migrant and integration patterns of the various immigrant national and ethnic groups. The problem is not so much to include culture as an explanatory variable but to downplay or even to totally ignore other crucial dimensions such as macroeconomic and structural factors like migration and integration policies. As Martens put it a long time ago, macro structural dimensions are more relevant than culture to explain migrants' integration in a given host society (Martens, 1976). Second, these immigrant national and ethnic group-to-group comparisons most often do not include the local non-immigrant national majority group. Therefore, it is almost impossible to identify the potential specificities of migrant groups by only comparing them to each other.

Besides immigrant national, ethnic and racial group-to-group comparisons, some comparative research prefers to focus on types and categories of migrants. Since historian Marcus Lee Hansen's work (Hansen, 1996), generations of migrants have often been compared. His 1938 essay on the problem of the third generation can indeed be read as a generational comparison within one immigrant group in the United States as to the dynamics of ethnic identification. His famous law predicting that ethnic identity will stay strong for the first generation, will almost disappear for the second generation and then become salient again for the third generation is the first cross-generational comparison in migration and post-migration studies. This type of work is certainly very insightful even though sociologists contested it for its lack of empirical grounding. However, it is hazardous to generalize Hansen's finding to other migrant groups, to other times and other places without additional cross-generation comparisons in many other settings. Still, it is now generally accepted that newcomers and following generations do differ in many respects from their parents' or grandparents' positions in the society of immigration. Not being technically migrants and having been socialized mainly in the receiving country of their ascendants are crucial characteristics of the following generations that distinguish them from the first generation, which impacts many issues such as education, work, identification and social integration. 
Finally, in many European countries, an implicit comparison is often made, more in public discourse than in academic research, between old and new migrants. This does not relate to the age of migrants but to the distinction between ancient waves of migrants and contemporary migration flows. Migrant workers, who came right after WWII were wanted, recruited. They were coming from culturally similar countries. Therefore, they easily integrated in the northern industrialized nations. On the contrary, today's migrants are largely unwanted. They originate in all parts of the world and they bring very different cultural and religious traditions to Europe that make their integration much more difficult if not totally impossible. This distinction between old and new migrants is a clear oversimplification. Old migrant workers were indeed recruited by northern European heavy industry to perform the $3 \mathrm{D}$ jobs. But they were often seen as too different culturally to integrate. Cultural difference is more a social construction than an objective undisputable reality. They also faced severe discrimination. Today's migrants are not all unwanted. There is even a competition between countries in order to recruit the highly qualified migrant works everybody wants, whatever their cultural differences may be.

Besides comparing people, researchers in migration and most-migration have also compared places as we shall see in the coming section.

\section{Comparing places}

Comparisons between places have first been country-to-country comparisons, or more specifically comparisons between national societies or nation-states. One of the first cross-national comparative endeavors in European migration studies is the project led by Hammar (1985). The collective volume edited by the Swedish political scientist systematically compared migration patterns and policies in six European countries (Germany, Switzerland, Britain, Sweden, the Netherlands and France). A few years later, Brubaker (1989) edited a book in which specialists compare the politics of citizenship in four European countries and in the two North American nation-states. The volume attracted a lot of attention on both sides of the Atlantic. Five years later, the book by Soysal (1994) entitled The Limits of Citizenship examined the patterns of incorporation in the same countries studied by Hammar and his colleagues ten years earlier. Her hypothesis about the emergence of a postnational form of membership influenced by human rights discourse provoked debates for several years 
after its publication. Another book to be mentioned is the Anglo-French comparison of the philosophies of integration published by Favell (1998).

These books were very useful in denationalizing migration and postmigration studies, which were historically very much nationally focused. In a way, they helped move away from methodological nationalism (Wimmer and Glick Schiller, 2002) as also suggested by the holders of a transnational research perspective. These books were followed by many others inspired by comparative political and sociological perspectives related to the Europeanization of migration debates. Each in it is own way constructed the idea that there were national models of immigration management and migrant incorporation. Except for Soysal's research, they were all quite normative or policy oriented and they did not really pay attention to grassroots incorporation processes from the migrants' points of view. They also neglected the importance of the local dimension in explaining the variation in integration processes.

Progressively, it appeared that the national model perspective was to be replaced by a focus on the local and city levels. This opened the space to city-to-city comparisons. In a collective book published in 2000, BodyGendrot, Martiniello (2000) and their colleagues compared the dynamics of integration and exclusion at the neighborhood level in several European cities by looking at the economic, the political and the social spheres. Since then, the number of comparative city-to-city research studies has increased exponentially on many different issues (political participation, housing, integration policies, etc.). In Europe, this movement is in part explained by purely academic reasons linked to the limitations of a nation-centered approach to immigration and integration. But it is also linked to the Europeanization of research through various funding mechanisms that more or less explicitly require this type of comparative study as well as sometimes the exchange of good practices and policy dialogues between local policy makers and researchers.

It is undisputable that integration takes place first at the local level. Often, local context matters more than national models to account for immigrant integration. This has been illustrated by these city-to-city comparisons. However, a few cities tend to attract a lot of attention while other cities are often ignored in comparative research. Amongst the top cities included in a large number of comparative studies one finds several capital cities of member states of the European Union such as Amsterdam, Berlin, London 
to which one can add the would-be capital city of a new would-be member state, Barcelona. There are many good reasons to try and compare these major European cities, which all claim to be global (Sassen, 2001). But beyond academic reasons, the omnipresence of these cities in comparative research is also the result of the mobilization of networks of researchers and of the proactivity of the local academic scenes often supported by local policy makers and politicians. However, migration has also had an impact on smaller, more provincial and less flashy cities, and it is increasingly so. It is therefore problematic that the recurrent comparisons of the same major cities distract attention from smaller and provincial cities. There are of course very stimulating exceptions, for example, the work of Bousetta (2010) on immigrants associations in Utrecht, Lille and Liège or the work by Romain Garbaye on ethnic minority politics in Birmingham, Lille and Roubaix (Garbaye, 2005). In addition, some cities have been included in specific issue comparisons such as Bradford, which has been in a way overstudied regarding Islam and Muslims since the Rushdie affair.

Next to country-to-county and city-to-city comparisons, continents can also be compared. There are many studies comparing countries located in different continents, and in particular the USA with European countries such as Britain, France or Germany (Joppke, 1999; Schain, 2012). But there are far fewer studies adopting a transcontinental perspective. In particular, scholars have argued in favor of more USA/European Union comparisons in the field of international migration and integration (Lafleur and Martiniello, 2009) in which the EU would be considered as an entity on the same footing with the USA with its internal complexity and diversity. EU-USA comparisons are generally not viewed very positively on the American academic side. Of course, American Europeanists study the European continent per se but very rarely venture into comparisons with the USA. When American scholars on migration are interested in Europe, they adopt the same perspective. They are more interested in explaining to Europeans what they can learn from Americans and they seldom consider that they could learn from European scholarship on migration. This patronizing attitude reflects the power of American academia but it is an obstacle facing the development of potentially valuable comparisons between the American and European migration and post-migration experiences. For example, some major American migration scholars like Hochschild and Mollenkopf (2009) have understood the potential strength of transatlantic comparisons through research partnerships between EU and USA scholars. 


\section{Other types of comparative research}

Besides comparing people and places on specific issues, research can also compare different time periods and the insights of different academic disciplines approaching the same topic. Historians of migration often develop those time comparisons. In Belgium, Anne Morelli has compared anti-immigrant discourse at the end of the 1990 and in the interwar period showing that the same derogatory categories were used in public discourse but they were applied to different national groups in the two time periods: what was said concerning Italians in Belgium in the 1930s was said about Moroccan immigrants in the 199os. Social historians like Bade (2003), Green (2002) and Lucassen (2006) regularly move back and forth between past and present in their studies by using theoretical tools borrowed from other social sciences such as sociology. This approach is highly stimulating and helpful in order to evaluate the specificity of each period time and of each migration pattern and to appreciate what is really new in migration and post-migration situations. This perspective clearly teaches us that what we too often consider to be entirely new in the field of migration is on the contrary often linked to previous events. It is therefore crucial to examine historical continuities and discontinuities in order to make sense of contemporary migration patterns and to design scenarios for the future of migration. However, the risk of anachronism must be taken into account in order to avoid systematically reaching the conclusion that nothing is really new in migration and post-migration situations.

Finally, we can compare the insights of the various disciplines interested in researching migration and its consequences. That is what Brettell and Hollified (2008) do in their edited book Migration Theory. Taking across disciplines. They show that the various academic disciplines pose particular research questions; they use different theories and units of analysis. Consequently, they produce different insights on multiple facets of the migration process.

The distinction between different types of comparative migration research we have just discussed is analytical. Researchers often design research that compare different categories of people in different places in different periods of time. However, comparative research in the field of migration and post-migration still needs to be developed. The next paragraph is dedicated to a discussion of the topics and types of comparison that could 
be promoted for a better understanding of the various dimensions of the migration process.

\section{Comparative Migration and Post-Migration Research: what still needs to be done?}

Comparative migration and post-migration research has developed considerably over the past 20 years. Many topics and issues have been covered in a comparative perspective sometimes in very big cross-national research programs financed by the European Union. Other times comparative projects have been smaller. In my view, in the future at least three types of comparisons should be developed further combining comparisons between people and places on a wide variety of issues linked to migration and postmigration situations. As a matter of fact, most issues in migration and post-migration studies would benefit by being examined in a comparative research framework. There are not comparative issues and topics, but only comparative research frameworks and designs.

The first type of comparative research that should be developed further is gender comparative research. Historically, both the issue of gender and the position of women have been too long neglected in migration and postmigration studies (Mahler and Pessar, 2006). This situation has been in part redressed with the emergence of feminist migration studies, which have precisely given a new visibility to women in migration processes. However, there are not yet enough truly gender comparative studies, examining and comparing systematically men and women with reference to specific issues in migration studies such as access to the labor market, access to nationality or cultural expressions, for example. After having neglected or totally ignored women in the migration process, after having moved to the other extreme by focusing exclusively on women, migration and post-migration studies should move more systematically towards a gender mainstreaming approach by systemically paying attention to the potential relevance of female-male comparisons.

The second type of comparative research that should be promoted further concerns city-to-city comparisons. We've seen above that city-to-city comparisons frequently involve the same usual suspect cities, which are often capital cities and gateway cities. The comparative studies have provided very interesting insights and results and shown the role of local contexts 
in the migration and integration processes. However, we need to add other cities and towns to the comparative studies. Migration increasingly affects all types of cities and not only gateway cities and capital cities. Today, migrants also settle in rural areas and not only in industrial regions like in the 1950s and 6os in Northern Europe (Jentsch and Simard, 2009). Of course, there are all sorts of research on many different local settings, but still too few systematic comparisons between the newer and less usual destinations of contemporary migration flows, namely smaller provincial cities and rural areas. These comparisons could be done within the same country or across country lines and even across continents. More south-south city-to-city comparisons would be particularly welcome.

The third type of comparison to be developed is intercontinental or interregional comparisons. We have very few north-south comparisons. Since many countries are simultaneously countries of immigration, of emigration and/or transit, it would make sense to see how far we could go in comparing, for example, the integration of newcomers in Morocco and in Spain. But further, I would like to make the case for the strengthening of transatlantic migration and post-migration studies, though specifically a transatlantic dialogue between the USA and the EU. There are certainly many differences between the USA and the EU that need to be taken into account when discussing an academic dialogue on migrations and post-migration situations between these two parts of the world. First, Americans consider themselves to be a "nation of immigrants", while the EU is a relatively young sui generis political construction adequately described by Wiener (1998) as a "non-state" composed of at least 28 nations, whose construction was completed before the big immigration waves. This difference is crucial because it frames the context in which immigration and integration happens. In the US, immigration is part of national history. It is at the core of the construction of the American nation even though there is a recurrent debate about the contribution of migration to society and about the necessity of attracting migrants in the future. Compared to this, in most EU countries immigration is still considered as an unwanted or unplanned addition to national societies constituted long before the arrival of migrants. In the US much more than in the EU, immigrants are considered to be citizens in the making, access to citizenship being the logical end of the migratory career (Martiniello and Rea, 2011).

Second, the US was - to put it in a simple and superficial way - a European colony for many years, whereas several member states of the EU were 
colonial or even imperial powers until the second half of the twentieth century. These different colonial and post-colonial experiences are related to current debates on immigrant integration and management of diversity. In particular, political participation and representation of minority groups in both societies is dealt with in different fashions, in part a question of different colonial traditions. In some European countries, "savoir-faire" in managing relations with colonized peoples was transferred to the metropolis to manage relations with immigrants.

Third, despite the many efforts undertaken on both sides of the Atlantic in terms of legislation and policies, ethnic and racial discrimination have persisted in both societies. However, there is nothing comparable to the historical American divide between blacks and whites in the EU. The legacy of slavery and racial segregation remains tangible in the US and it remains relevant in understanding the debates over the integration of immigrants even in the Obama era.

Fourth, the place of religion in society and politics remains quite different in the US and in the EU. In the US society, asserting a religious identity and displaying religious convictions in public is considered to be normal and not necessarily problematic. On the contrary, expressions of atheism are not well accepted socially. It is no surprise in the "Nation under God". On the contrary, in several EU counties where the sociological secularisation process in society was particularly powerful, the public expressions of faith often cause controversies and debates even though the individual right to a religion is guaranteed. Politically, the US has a long tradition of protecting religious minorities, many of which were expelled from Europe in the past. The principle of a separation of politics from religion is not understood in the same way in Europe and in the US. It is formally understood in a strict sense in the US and in some European countries like France. This is much less the case in many European countries like Greece, Germany and the Netherlands, just to take three examples. But de facto the idea according to which the political arena should be "religion-free" remains more potent in Europe than in the US. Those differences are crucial to understanding the different ways in which both societies respond to religious claims made by immigrant communities.

Fifth, in general terms, there are huge differences between welfare provisions and the social security systems in the US and in the EU even though a process of relative convergence has probably started. In some EU countries, 
unemployment benefits are provided for a long period of time. Access to health services is easier and cheaper than in the US. The same holds for access to education from pre-school to university. These differences have an impact both on the economic integration of immigrants and also on the attitude of the local populations towards immigrants. In the EU more than in the US, immigrants are often unfairly accused of taking advantage of the welfare system.

Sixth, the question of national unity is not really relevant in the American context. Apart from some very marginal political groups, nobody seriously questions the unity of the state. It is of major concern in several EU member states such as Belgium, Italy, and Spain and, to a lesser extent, the United Kingdom. Autonomous, regionalist, separatist and nationalist movements challenge either the European integration process or national unity at the highest levels of political institutions. Belgium is probably the most notable example in that respect. The longstanding dispute between French-speaking and Flemish-speaking Belgians is far from being settled and it jeopardizes the permanence of the state that hosts the capital city of the EU. Seeking integration in a disunited society or in a society characterized by a relatively strong national identity is certainly not the same.

This list of differences between the US and the EU is not exhaustive. However, it is obvious that they have an impact on the migration and integration process and also on the public debates on immigration and integration. But beyond this, there are also similarities between the two societies that call for a dialogue between them. Both the US and the EU are magnets for millions of potential immigrants from different geographical regions. Immigration from Latin America is stronger in the US and immigration from Africa is more important in the EU. But migration patterns and routes are increasingly diversified and despite economic, financial and social crises, both societies continue to attract migrants year after year. Very little is expected to change in the future. As a consequence, both the US and the EU are de facto multicultural, multiracial, multi-ethnic and multi-faith societies. The US has entered a process of diversification of its diversity (Hollinger, 1995) while the EU has stepped into "super-diversity" (Vertovec, 2007) even though the configuration of diversity is different in each case. Both in US and in EU cities similar contradictory trends can be observed. On the one hand, ethnic, racial and religious separation and segregation are a reality. But, on the other, intercultural, interracial and interfaith exchanges are also developing. Trends towards fragmentation and trends towards cohesion 
and integration develop in parallel, even if the economic crisis favours the former. The growth of economic inequalities is another common feature of both societies. Poverty, exclusion and marginalization are on the rise and they affect immigrants, ethnic minorities and majorities differently. One thing is sure: when economic inequalities and ethnic divisions overlap, the risk for ethnicized social conflicts is much higher.

Beyond differences and similarities, the US and the EU seem to face the same old challenges: how to manage both internal and international populations movements? How to integrate an increasingly diverse society shaped by migration? How to combine the respect for diversity with social and economic cohesion? The issue of the integration of immigrants is part of this broad challenge by which both societies need to rethink their democratic pluralism. They, therefore, would both gain by learning from each other how to respond to the same questions in different contexts. In my view, a journal like Comparative Migration Studies could take on this challenge but it should certainly move much further in the direction of broader and world scale comparisons including south-south comparisons.

It is undisputable that a journal like the Comparative Migration Studies is welcome in the densifying forest of publications on migration and postmigration situations in order to take up the challenges of comparative research in this field. This first issue illustrates in part the variety of topics and issues that can lead to comparative research as well as the various types and scopes of comparisons for a better knowledge of past, present and future migration dynamics.

\section{References}

Bade, K., (2003). Migration in European History, Oxford, Blackwell.

Bloemraad, I., (2013). The Promise and Pitfalls of comparative Research Design in the Study of Migration, Migration Studies, Vol. 1, Number 1, 27-46.

Body-Gendrot, S. and Martiniello, M. (Eds.), (2000). Minorities in European Cities. The Dynamics of Social Integration and Social Exclusion at the Neighbourhood Level, Houndmills, Macmillan, CRER.

Bousetta, H., (2010). 'Political Dynamics in the City. Three case studies'. In M. Martiniello and J. Rath (Eds.), Selected Studies in International Migration and Immigrant Incorporation, Amsterdam, Amsterdam University Press, IMISCOE Textbooks, 355-370.

Brettell, C. B. and Hollifield, J. H. (Eds.), (2008). Migration Theory. Talking across Disciplines. New York and London, Routledge. 
Brubaker, W. R., (Ed.), (1989). Immigration and the Politics of Citizenship in Europe and North America, New York, University Press of America.

Castles, S. and Miller, M., (2009). The Age of Migration. International Population Movements in the Modern World. Fourth Edition. Revised and updated, New York, Palgrave Macmillan.

Favell, A., (1998). Philosophies of Integration. Immigration and the Idea of Citizenship in France and Britain. Macmillan, CRER, Houndmills and Coventry.

Fitzgerald, D., (2012). 'A Comparativist Manifesto for International Migration Studies', Ethnic and Racial Studies, Vol.35 number 10, 1725-1740.

Garbaye, R., (2005). Getting into Local Power. The Politics of Ethnic Minorities in British and French Politics, Oxford, Balckwell Publishing.

Green, N. T., (2002). Repenser les migrations, Paris, Presses Universitaires de France.

Hammar, T. (Ed.), (1985). European Immigration Policy. A comparative study, Cambridge, Cambridge University Press.

Hansen, M. L., 1996. 'The Problem of the Third Generation Immigrant (1938)', In W. Sollors (Ed.), Theories of Ethnicity. A Classical Reader, London MacMillan, 202-215

Hollinger, D., (1995). Postethnic America: Beyond Multiculturalism, New York (N. Y.), Basic Books.

Hochschild, J. and Mollenkopf, J. (Eds.), (2009). Bringing oustiders in. Transatlantic Perspectives on Immigrant Political Incorporation, Ithaca, Cornell University Press.

Jentsch, B. and Simard, M. (Eds.), (2009). International Migration and Rural Areas: Cross-National Comparative Perspectives, Farnam and Burlington, Ashgate.

Joppke, C., (1999). Immigration and the Nation-State: The United States, Germany, and Great Britain, Oxford, Oxford University Press.

Lafleur, J.M. and Martiniello, M. (Eds), (2009). The Transnational Political Participation of Immigrants. A Transatlantic Perspective, London, Routledge.

Lucassen, L., (2006). The Immigrant Threat: The Integration OfOld And New Migrants In Western Europe Since 1850, Urbana, Illinois University Press.

Mahler, S. and Pessar, P., (2006). 'Gender Matters: Ethnographers Bring Gender from the Periphery toward the Core of Migration Studies', International Migration Review, Vol. 40, number $1,27-63$.

Martens, A., (1976). Les immigrés. Flux et reflux d'une main-d'oeuvre d'appoint, Louvain, P.U.L., Editions Vie Ouvrière.

Martiniello, M., (2012). 'Immigrant Integration and Multiculturalism in Belgium' In R. Taras (Ed.), Challenging Multiculturalism. European Models of Diversity, Edinburgh, Edinburgh University, 120-137.

Martiniello, M. and Rea, A., (2011). 'Des flux migratoires aux carrières migratoires,

Éléments pour une nouvelle perspective théorique des mobilités contemporaines',

SociologieS, Dossiers, Migrations, pluralisation, ethnicisation des sociétés contemporaines, on line on 18 october, URL: http://sociologies.revues.org/index3694.html, $11 \mathrm{p}$.

Morelli, A. (Ed.), (2004). Histoire des étrangers et de l'immigration en Belgique de la préhistoire à nos jours, Bruxelles, Couleur Livres.

Sassen, S., (2001). The Global City. London, New York and Tokyo, New Haven, Princeton University Press, second edition.

Sayad, A., (2010). 'Immigration and 'State Thought" In M. Martiniello and J. Rath (Eds.), Selected Studies in International Migration and Immigrant Incorporation, Amsterdam, Amsterdam University Press, IMISCOE Textbooks, 165-180.

Schain, M., (2012). The Politics of Immigration in France, Britain and the United States. A Comparative Study, New York, Palgrave MacMillan, Second Edition

Soysal, Y., (1994). Limits of citizenship. Migrants and Postnational Membership in Europe, Chicago, University of Chicago Press. 
Stanfield II, J. H., (1993). 'Epistemological Considerations' In J. H. Stanfield II and R. M. Dennis (Eds.), Race and Ethnicity in Research Methods, Newbury Park, London and New Delhi, Sage Publications, 16-36.

Steinberg, S., (2001). The Ethnic Myth. Race, Ethnicity and Class in America, Boston, Beacon Press, Third Edition.

Tillie, J., (1998). 'Explaining migrant voting behaviour in the Netherlands. Combining the electoral research and ethnic studies perspective, Revue Européenne des Migrations Internationales, Vol. 14, numéro 2, 71-95

Vertovec, S., (2007). Super-diversity and its implications, Ethnic and Racial Studies, vol.30, ${ }^{\circ} 6$, 1024-1054.

Wiener, A., (1998). European Citizenship' Practice. Building Institutions of a non-state. Boulder: Westview Press.

Wimmer, A. and Glick-Schiller, N., (2002). 'Methodological nationalism and beyond: nation-state building, migration and the social sciences'. Global Networks, A Journal of Transnational Relations, Vol. 2, number 4, 301-34.

\section{About the author}

Marco Martiniello, FRS-FNRS and CEDEM, University of Liège, Liège, Belgium. E-mail: M.Martiniello@ulg.ac.be.

Ph: oo 32 (o) 43663040 - Fax:oo 32 (o) $4366475^{1}$

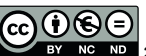

This is an Open Access article distributed under the terms of the Creative Commons Attribution License (http:// creativecommons.org/licenses/by/2.o), which permits unrestricted use, distribution, and reproduction in any medium, provided the original work is properly cited. 